\title{
Magnetic Aging, Anomalous and Hysteresis Losses
}

\author{
Adriano Alex de Almeida* ${ }^{a}$, Fernando José Gomes Landgraf ${ }^{b}$ \\ ${ }^{a}$ Aperam South America, Timóteo, MG, Brasil \\ ${ }^{b}$ Departamento de Engenharia Metalúrgica e de Materiais, Universidade de São Paulo, São Paulo, SP, \\ Brasil
}

Received: July 18, 2018; Revised: December 02, 2018; Accepted: February 15, 2019

In this study the magnetic aging effect on anomalous and hysteresis loss was investigated, as well as its effect on domain morphology. For this purpose, non-oriented fully processed electrical steel with 2.3 wt. $\% \mathrm{Si}-79 \mathrm{ppm} \mathrm{C}$ and non-oriented semi-processed electrical steel annealed at $750{ }^{\circ} \mathrm{C}$ for 5 hours with 0.4 wt. $\% \mathrm{Si}-340 \mathrm{ppm} \mathrm{C}$ were aged at $150{ }^{\circ} \mathrm{C}$. The anomalous loss has been shown to be less affected by the magnetic aging. The increasing of the excitation frequency has induced a reduction on anomalous loss measured on aged steel. All increases presented by total loss were provided by hysteresis loss. The main disturbance in magnetic domain morphology appears to have been caused by different grain orientation.

Keywords: aging effect, anomalous loss, magnetic domain, non-oriented steel.

\section{Introduction}

The magnetic aging effect is known to be deleterious to magnetic properties of electrical steels ${ }^{1}$. In order to avoid this effect, electrical steel has been produced with a reduced carbon content $(<20 \mathrm{ppm})$.

The main cause of carbide precipitation on non-oriented electrical steel is the increasing energy relative to hysteresis loss $\left(\mathrm{W}_{\mathrm{h}}\right)^{2}$. This effect is a consequence of domain wall pinning by iron carbides during the hysteresis process.

The impediment to domain wall movement during the magnetizing process under increasing excitation frequencies may give rise to domain wall nucleation to maintain the continuous magnetizing process. It will result in an increment of domain wall density, which means that anomalous loss is less sensitive to aging than hysteresis loss. Therefore, the magnetic aging effect on anomalous and hysteresis loss was studied.

The measurement of the aging index was carried out according to equation 1 .

$$
A I \%=\frac{W_{\text {before- aging }}-W_{\text {aging }}}{W_{\text {aging }}}
$$

\section{Materials and Methods}

The materials used in this paper were non-oriented fully processed electrical steel (S79) and non-oriented semi-processed electrical steel (S340). The grain size was measured by the intercept method according to ASTM-E112 ${ }^{3}$. The electrical resistivity was measured according to ASTM-A72 ${ }^{4}$. The chemical composition and microstructural characteristics are shown in Table 1 and Table 2, respectively.
Table 1. Chemical composition (wt.\%) for alloys S79 and S340.

\begin{tabular}{lccccc}
\hline Alloy & C & Si & S & Mn & N \\
\hline S79 & 0.0079 & 2.04 & 0.002 & 0.43 & 0.0038 \\
S340 & 0.034 & 0.4 & 0.012 & 0.31 & 0.026 \\
\hline
\end{tabular}

Table 2. Microstructural characteristics for alloys S79 and S340.

\begin{tabular}{lcccc}
\hline Alloy & $\begin{array}{c}\text { Grain } \\
\text { size }(\boldsymbol{\mu m})\end{array}$ & $\begin{array}{c}\text { thickness } \\
(\mathbf{m m})\end{array}$ & $\left(\mathbf{K g} / \mathbf{m}^{\mathbf{3}}\right)$ & $\boldsymbol{\rho}(\boldsymbol{\mu} \Omega \mathbf{c m})$ \\
\hline S79 & 62 & 0.53 & 7716 & 40 \\
S340 & 55 & 0.62 & 7830 & 18.3 \\
\hline
\end{tabular}

In order to promote recrystallization and grain growth, alloy S340, was annealed under Ar atmosphere at $750{ }^{\circ} \mathrm{C}$ for 5 hours. Heat treatment of alloy S79 was done under the same conditions, however, in this case the aim was stress relief. The samples were quenched to avoid the precipitation, then aged at $150^{\circ} \mathrm{C}$ in the time range of 3-365 hours. The microstructural and magnetic properties were measured during the aging annealing. Measurements of carbide size was carried out from the largest dimension.

To measure magnetic losses, an Epstein frame was used with peak induction of 1 and $1.5 \mathrm{~T}$ and frequencies to $180 \mathrm{~Hz}$ for total losses $\left(\mathrm{W}_{\mathrm{t}}\right)$ and $0.005 \mathrm{~Hz}$ for quasi-static loss $\left(\mathrm{W}_{\mathrm{h}}\right)$. The measurements were carried out according to ASTM-A343 ${ }^{5}$.

\section{Results and Discussions}

\subsection{Carbides and quantitative stereology}

Two types of precipitates were observed after 100 hours at $150^{\circ} \mathrm{C}$, one of which is shown in Fig. 1a. This precipitate, epsilon carbide, has a $\{100\}_{\alpha}$ habit plane and grows on all 
three of the $\{100\}_{\alpha}$ planes ${ }^{6,7}$. At higher carbon content, alloy (S340) cementite and epsilon carbide coexist. Cementite forms on $\{011\}_{\alpha}$ growing in $\langle 111\rangle_{\alpha}$, Fig. $1 b^{6,7}$.

Due to the time range, temperature, chemical composition and the result shown in Fig. 1a of alloy S340 it is reasonable to assume that $\mathrm{F}_{3} \mathrm{C}$ was already present before 100 hours of aging. This hypothesis can be based on Leslie ${ }^{8}$. The author has reported cementite precipitation in alloys with $140 \mathrm{ppm}$ of carbon content aged at $150{ }^{\circ} \mathrm{C}$ for 100 minutes. The presence of only epsilon carbide on alloy S79 was expected due to silicon content. It has been reported that silicon raises the transition temperature from epsilon carbide to cementite ${ }^{6}$.

The volumetric fraction measurement shows a maximum at 175 hours of aging for both alloys. After this aging time the $\mathrm{F}_{\mathrm{V}}$ decreases indicating a coarsening of carbides as shown Fig. 2a and 2b.

In Fig, $3 \mathrm{a}$ and $3 \mathrm{~b}$ it is possible to see that a carbide size peak appears for S79 after about $275 \mathrm{~h}$ of aging. In alloy S340 the carbide size peak appears during the early stages of ageing, 175 hours. After these times the increase of carbide size reached a plateau value. It is reasonable to assume that carbide size may have been overestimated due chemical etching ${ }^{9}$. The carbide size obtained in alloy S79 can be compared with the results from ${ }^{10}$ that obtained mean carbides size of $1 \mu \mathrm{m}$ for alloy with $2 \mathrm{wt} . \% \mathrm{Si}$ and $32 \mathrm{ppm} \mathrm{C}$ aged at $180^{\circ} \mathrm{C}$ from 60 hours. However, silicon steels with $60 \mathrm{ppm}$ of $\mathrm{C}$ content aged at $225^{\circ} \mathrm{C}$ presented a carbide size peak before 10 hours of treatment, results obtained from computer simulation ${ }^{11}$.
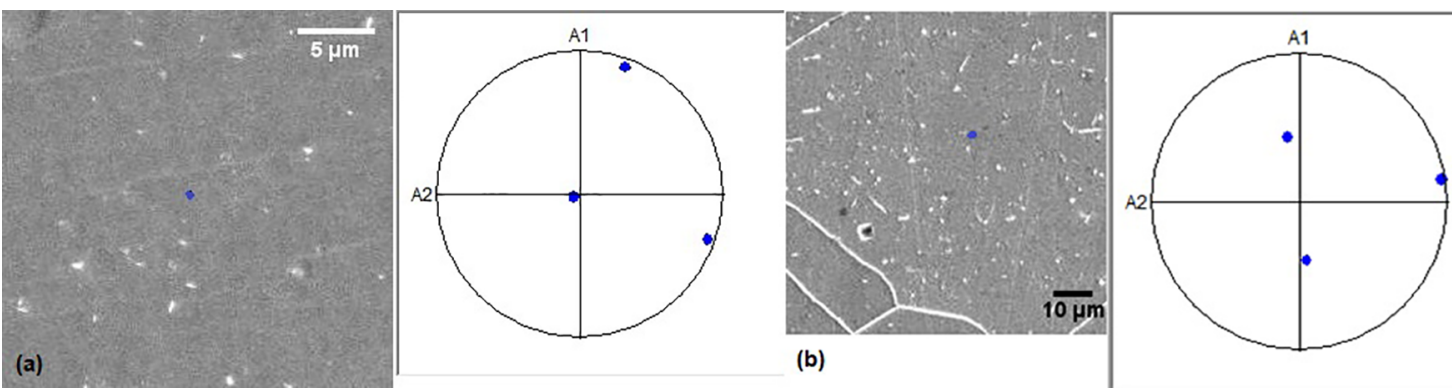

Figure 1. (100) pole figure of S79 and S340 after 100 hours at $150^{\circ} \mathrm{C}$. a) $\varepsilon$ carbide present in habit plane. b) Cementite and epsilon carbide coexist, each one in its habit plane and growing direction.
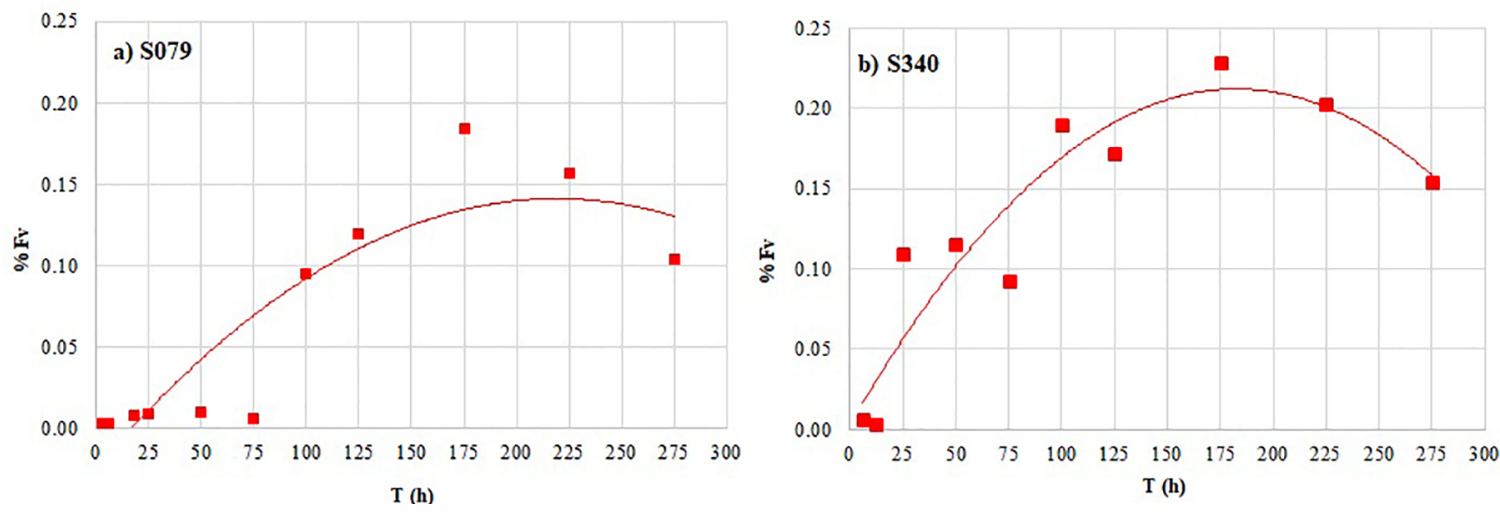

Figure 2. Measurement of volumetric fraction from alloys S79 (a) and S340 (b) against aging time.
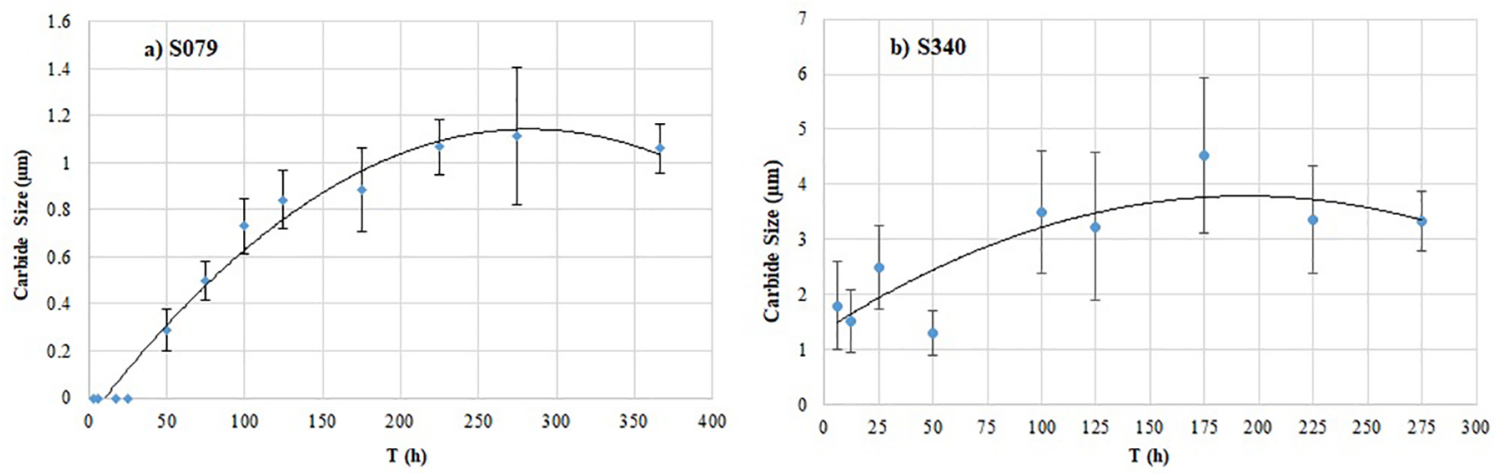

Figure 3. Size of carbides. Measurements carried out from the largest dimension. 
The carbide size difference between alloys is from the higher silicon content in S79. It has been reported that silicon acts on growth kinetic of carbides and tends to stabilize epsilon carbides ${ }^{6,12}$.

\subsection{Hysteresis losses}

The aging time of the volumetric fraction maximum and harmful carbide size ${ }^{1}$ does not match the peak of $\mathrm{AI} \%$ from hysteresis loss as shown in Fig. 4a and 4b. This result indicates that for a non-spherical particle the maximum deleterious effect is a combination of habit plane of carbide, growth direction and a demagnetizing factor.

The effect of magnetic aging on hysteresis loss has been different under 1 and 1.5T. The presence of carbides affects significantly the $\mathrm{W}_{\mathrm{h}}$ under $1 \mathrm{~T}$, as shown for the AI\% in Fig. 4. It is likely that these effect came from increases in the coercive field ${ }^{2}$. A better observation based on the aging effect under different inductions can be done by applying the concept of hysteresis subdivision ${ }^{13}$. In this method, a hysteresis area is divided by the maximum permeability in the area of low induction (Li) and high induction (Hi). The losses of low induction areas associated with a field necessary to move $180^{\circ}$ walls ${ }^{13,14}$ increased, indicating a domain wall pinning by iron carbides, as shown in Fig. $5 \mathrm{a}$ and $5 \mathrm{~b}$.

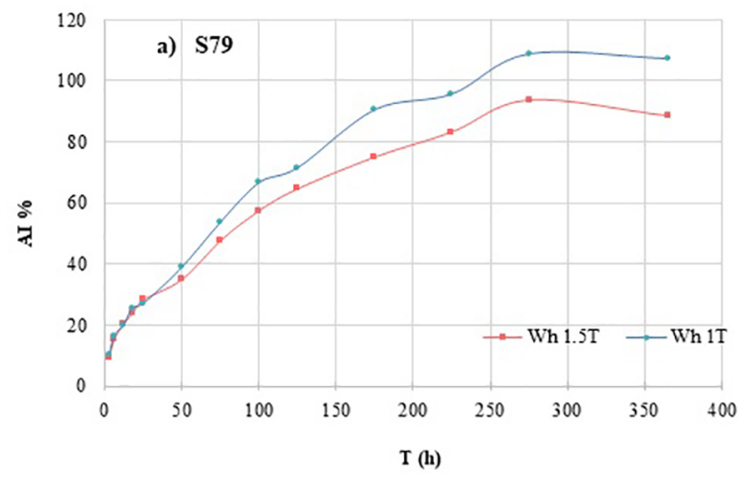

Figure 4. Aging index of hysteresis loss.

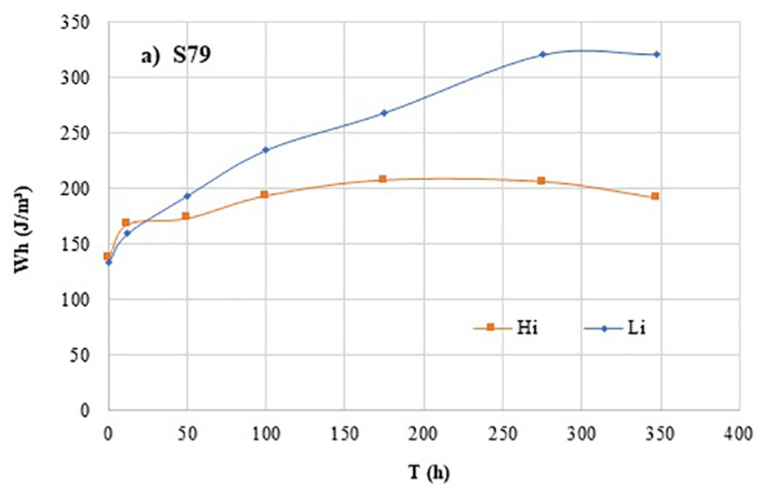

The high induction area associated with nucleation, rotation and annihilation of domain was less sensitive to aging as shown in Fig. 5a and 5b. However, a slight increase can be seen in high induction areas. It is possible that the annihilation and nucleation phenomenon may have been affected by carbides ${ }^{15}$.

The behavior of the loss in low and high induction is similar to the grains size effect, as shown in ${ }^{13}$. The grain size decrease induces an increase in Li area against weak changes in Hi area ${ }^{13}$, this effect is similar to carbides presence. Thus, the increasing of low induction losses is due the coercive field increase.

\subsection{Anomalous losses}

The anomalous loss was obtained from the classical equation $\mathrm{Wa}=\mathrm{Wt}-\mathrm{Wh}-\mathrm{Wp}$. The consequence of the aging on $\mathrm{W}_{\mathrm{a}}$ is shown in Fig. $6 \mathrm{a}$ and $6 \mathrm{~b} \mathrm{S340}$ and Fig. $7 \mathrm{a}$ and $7 \mathrm{~b}$ $\mathrm{S} 79$. It is noted that $\mathrm{AI} \%$ of anomalous loss at $1.5 \mathrm{~T}$ is less than under $1 \mathrm{~T}$. It is possible to observe that the increase of excitation frequency tends to reduce the $\mathrm{W}_{\mathrm{a}}$ for $\mathrm{S} 79$ under $1 \mathrm{~T}$ and $1.5 \mathrm{~T}$, however for S340 similar behavior is shown at 1.5 T. An analogous behavior has been shown for the effect of plastic deformation on anomalous losses, in this paper the Wa tend to zero when excitation frequency increase, for samples above $2 \%$ cold rolling ${ }^{16}$.
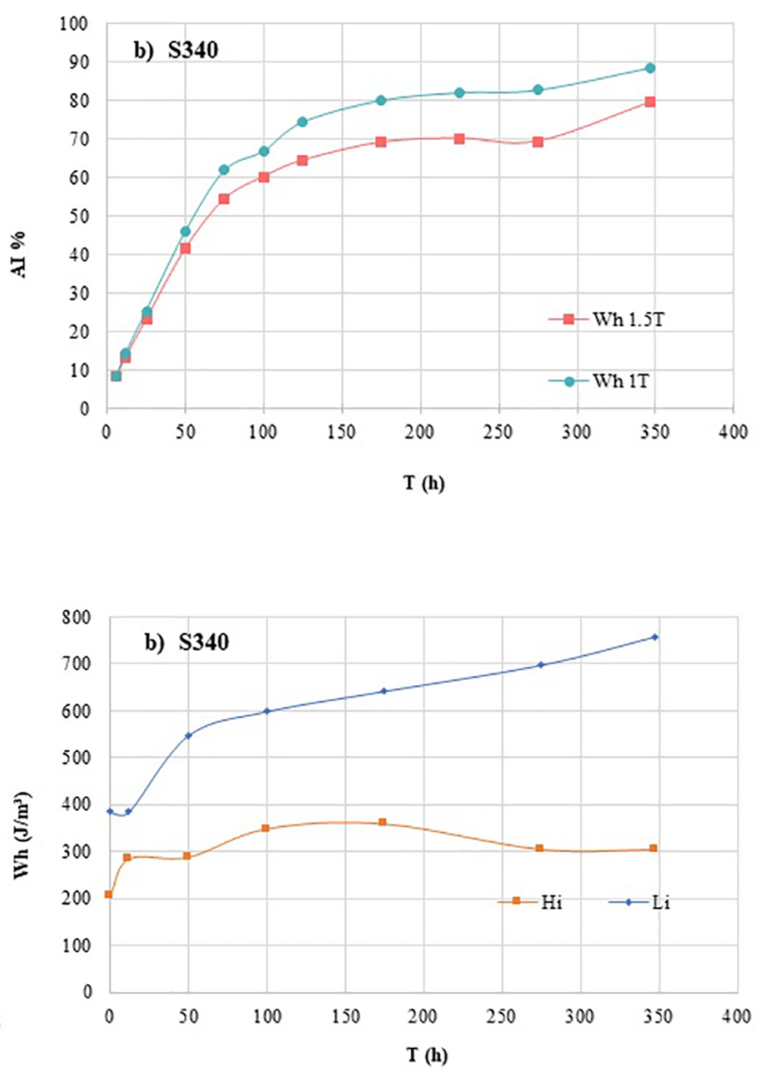

Figure 5. Hysteresis loss (1.5T) subdivision using the induction at maximum permeability as the limit between the low-induction and the high-induction regions maximum. 

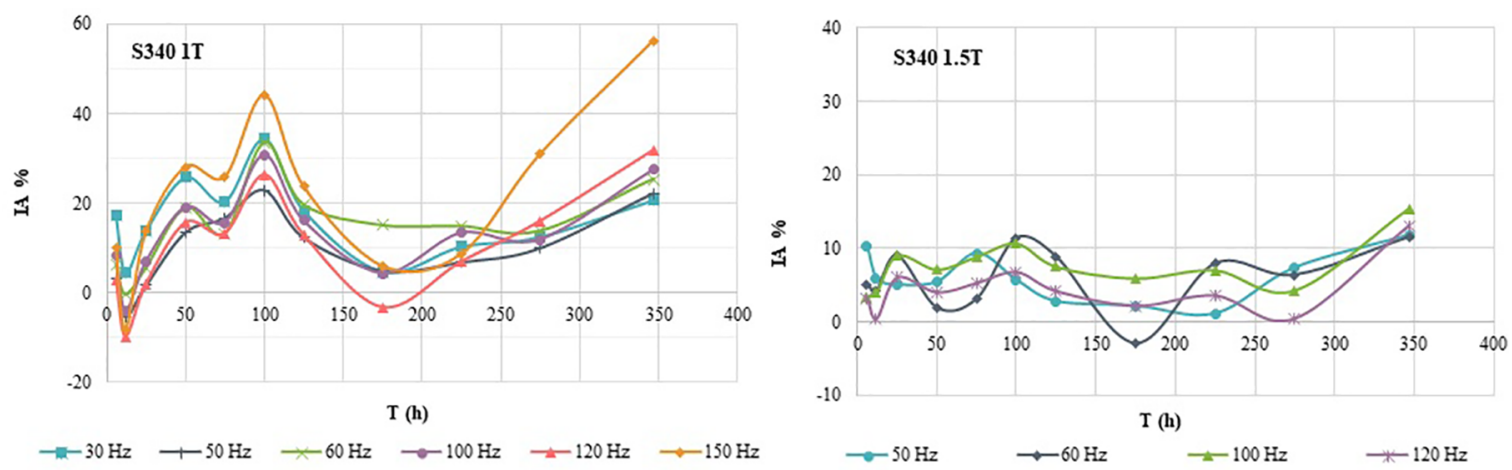

Figure 6. Anomalous losses from different aging time against the excitation frequency, for steel S340.
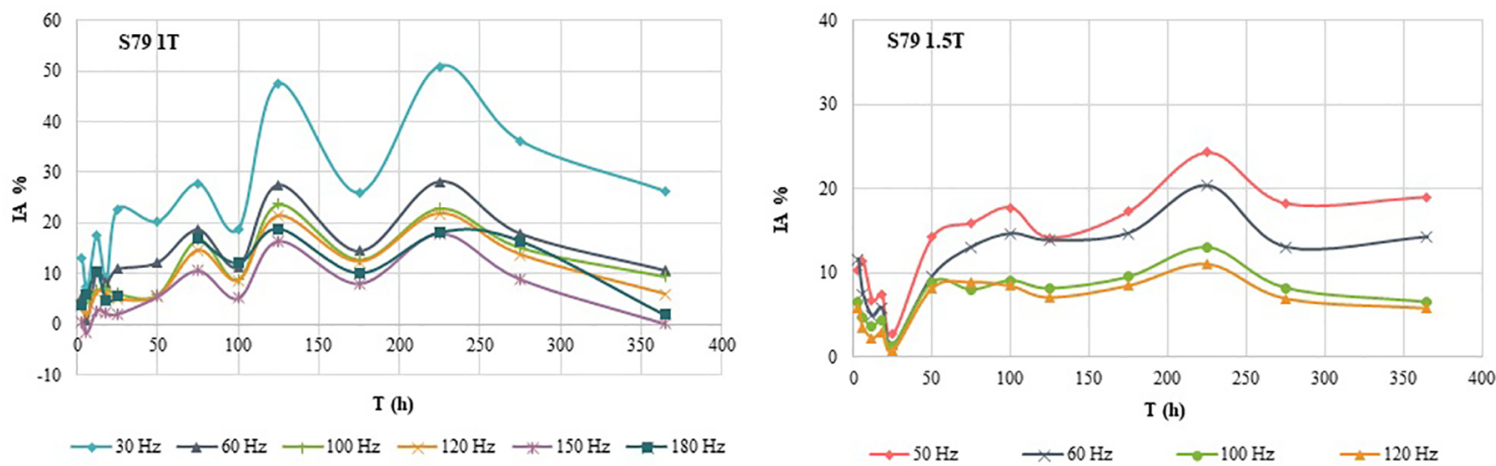

Figure 7. Anomalous losses from different aging time against the excitation frequency, for steel S79.

The decreasing of the aging index through increasing excitation frequency, as shown in Fig. 7, may have been caused by a rise in domain wall density ${ }^{17}$. This hypothesis is based on an assumption that the magnetizing process is continuous: the increase of excitation frequency causes a rise in domain wall velocity, nevertheless, now domain wall pinning at the carbides. As a magnetizing process must be continuous, the wall nucleation processes may be activated which in turn promotes the rise of wall in this process. Therefore, it is plausible to assume that a nucleation of a new domain wall in an aging sample is favored by carbides and this phenomenon increases is directly proportional to excitation frequency.

Although difference in microstructural features between alloys S340 and S79 exist, the effect of aging on anomalous loss seems to have promoted the similar behavior. Thus, the main increase in total loss has been caused by hysteresis loss.

\subsection{Interaction between carbide and domain wall}

Two energies control the interaction between the domain wall and particles. The first one is domain wall energy and depends on particles volume and the second one is the demagnetizing field. This field comes into action when nonmagnetic particles are present in the ferromagnetic matrix, in which magnetic dipole of self-energy arises inside it ${ }^{18}$.
The intensity of the demagnetizing field depends on particle morphology (demagnetization factor) and the angle between the applied field and its major axes.

When particle diameter is smaller than wall thickness it is completely enclosed by a domain wall the energy provide from demagnetizing field is reduced to a minimum value. The energy wall is lower according the particle volume.

For the case in which particle diameter is equal to wall thickness, the interaction achieved its maximum. Thus, deleterious effect since the magnetostatic energy is much stronger that the energy wall effect ${ }^{18}$.

For carbide larger than wall thickness, the magnetostatic energy is not fully reduced, on the other hand, the energy wall's value is lower according particle volume. In this case, closure domains may have nucleated around a particle to minimize free magnetic poles ${ }^{15,18}$.

In order to identify a possible domain wall refinement, the magneto-optical Kerr effect technique was used as shown in Fig. 8, 9 and 10.

In Fig. 8, the main difference in domains morphology seems to have been provided by misorientation and grain orientation, which corroborates with previous results from literature ${ }^{19}$.

Pitting corrosion promoted a disturbance on the magnetic domain, as shown in Fig. 9. However, it was not possible to 


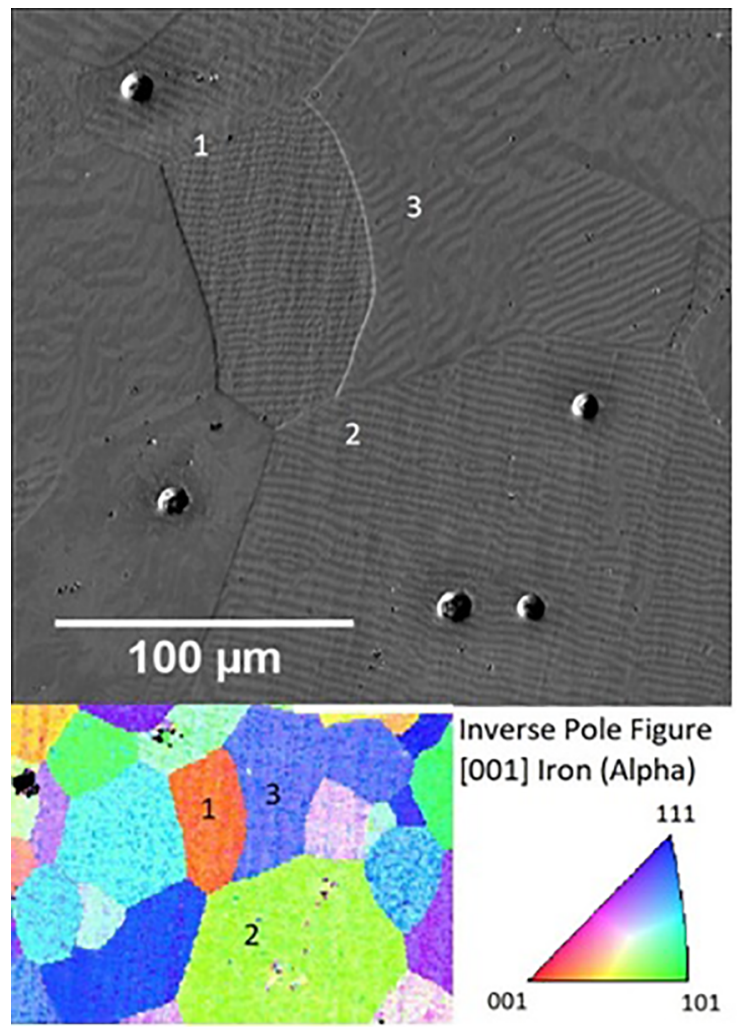

Figure 8. Effect of texture and pitting corrosion on magnetic domain morphology of $\mathrm{S} 79$ aging at $150^{\circ} \mathrm{C}$ by 100 hours.

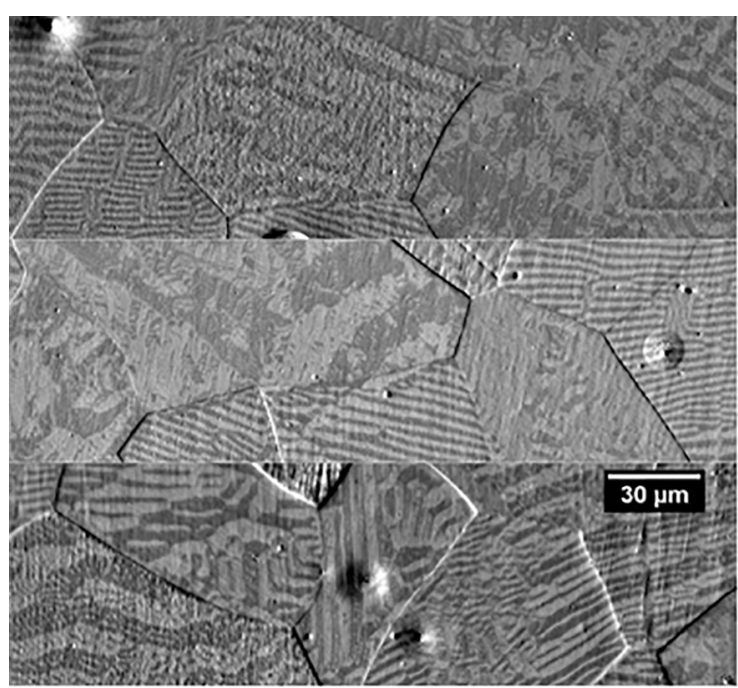

Figure 9. Changes on magnetic domain morphology caused by grain boundaries and texture, S79 before aging.

see any closure domain around them. It was expected for particles whose size is larger than the domain wall thickness to be able to promotes closure domain nucleation ${ }^{15,18}$.

It is admissible that field of grain boundaries supplants the magnetostatic energy that comes from particles, preventing

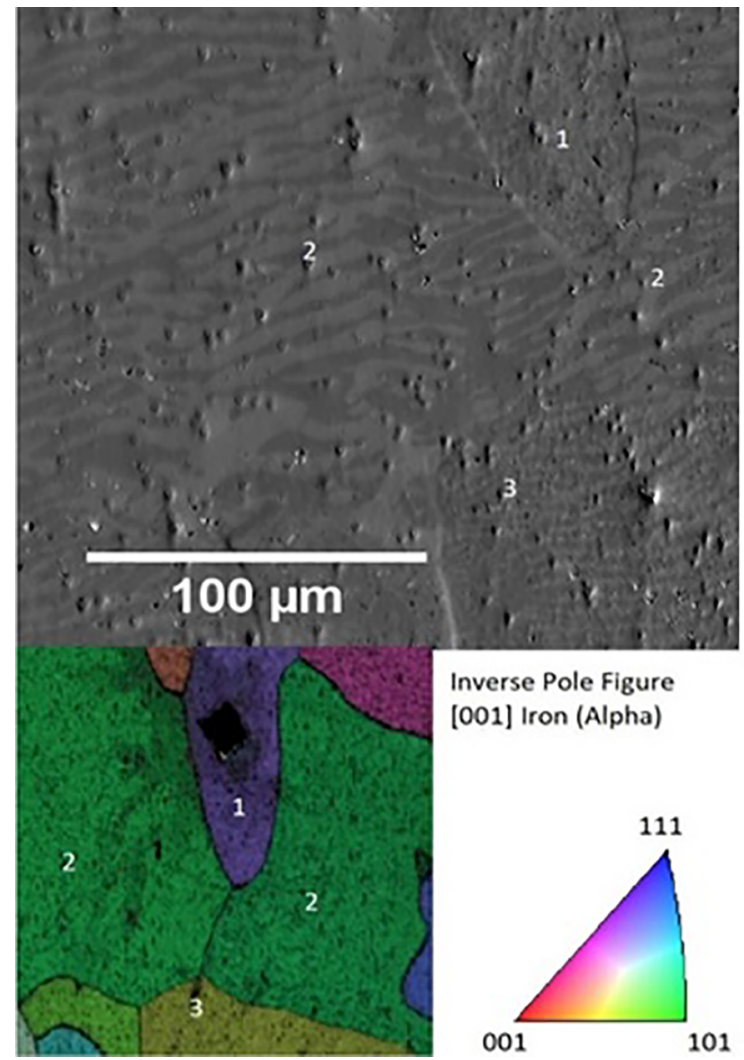

Figure 10. Effect of texture and pitting corrosion on magnetic domain morphology of $\mathrm{S} 340$ aging at $150^{\circ} \mathrm{C}$ by 100 hours.

a nucleation of new domains walls under an absence of external fields.

In Fig. 10 is shown the image from S340 is shown a massive presence of pitting corrosion can be seen, however, the domain morphology remains the same as alloy S79.

It is not possible to identify changes in domain morphology due to the presence of carbides, as shown in Fig. 8, 9 and 10. It is likely that major changes will only occur in magnetizing processes promoting the increase of hysteresis loss and keeping anomalous loss constant.

\section{Summary}

The increase in total loss from aged samples was provided by increases in hysteresis loss. At peak induction of $1.5 \mathrm{~T}$ and high excitation frequency anomalous losses were reduced. The domain morphology was changed a little by pitting corrosion presence. The texture remains the most important source of modification in domain morphology.

\section{Acknowledgement}

The authors would like to thank CAPES, CNPq, IPT and Aperam South America, Fundação de Amparo à Pesquisa do Estado de São Paulo (FAPESP) no 2015/15559-9. 


\section{References}

1. Marra KM, Landgraf FJG, Buono VT. Magnetic losses evolution of a semi-processed steel during forced aging treatments. Journal of Magnetism and Magnetic Materials. 2008;320(20):e631-e634.

2. de Campos MF, Emura M, Landgraf FJG. Consequences of magnetic aging for iron losses in electrical steels. Journal of Magnetism and Magnetic Materials. 2006;304(2):e593-e595.

3. ASTM International. ASTM E112-12 - Standard Test Methods for Determining Average Grain Size. West Conshohocken: ASTM International; 2012.

4. ASTM International. ASTM A712-14 - Standard Test Method for Electrical Resistivity of Soft Magnetic Alloys. West Conshohocken: ASTM International; 2014.

5. ASTM International. ASTM A343 / A343M-14 - Standard Test Method for Alternating-Current Magnetic Properties of Materials at Power Frequencies Using Wattmeter-Ammeter-Voltmeter Method and 25-cm Epstein Test Frame 1. West Conshohocken: ASTM International; 2014.

6. Leslie WC, Rauch GC. Precipitation of carbides in low-carbon Fe-AI-C alloys. Metallurgical Transactions A. 1978;9(3):343349.

7. Marra KM, Alvarenga EA, Buono VTL. Magnetic aging a nisotropy of a semi-processed non-oriented electrical steel. Materials Science and Engineering: A. 2005;390(1-2):423-426.

8. Leslie W. The quench-aging of low-carbon iron and ironmanganese alloys an electron transmission study. Acta Metallurgica. 1961;9(11):1004-1022.

9. Michal GM, Slane JA. The kinetics of carbide precipitation in silicon-aluminum steels. Metallurgical Transactions A. 1986;17(8):1287-1294.
10. de Oliveira Júnior JR. Estudo do envelhecimeto magnético em aços silício de grão não orientado 2\%Si. [Dissertation]. Belo Horizonte: Federal University of Minas Gerais; 2014.

11. de Oliveira Júnior JR, Monteiro RA, Paolinelli SC, Cota AB. Kinetics of Magnetic Ageing of $2 \% \mathrm{Si}$ Non-oriented Grain Electrical Steel. Materials Research. 2018;21(1):e20170575.

12. Ray SK, Mohanty ON. TEM Investigation of Carbide Precipitation in Low Carbon Steels Containing Silicon. Transactions of the Japan Institute of Metals. 1983;24(2):81-87.

13. Landgraf FJG, de Campos MF, Leicht J. Hysteresis loss subdivision. Journal of Magnetism and Magnetic Materials. 2008;320(20):2494-2498.

14. Almeida AA, Perassa LS, Rodrigues DL, Nishikawa TSP, Landgraf FJG, Paolinelli SC, et al. Excess Loss Localization on the Hysteresis Curve. IEEE Transactions on Magnetics. 2014;50(4):6300404.

15. Goodenough JB. A Theory of Domain Creation and Coercive Force in Polycrystalline Ferromagnetics. Physical Review. 1954;95(4):917-931.

16. Rodrigues DL Jr, Silveira JRF, Gerhardt GJL, Missell FP, Landgraf FJG, Machado R, et al. Effect of Plastic Deformation on the Excess Loss of Electrical Steel. IEEE Transactions on Magnetics. 2012;48(4):1425-1428.

17. Houze GL Jr. Domain-Wall Motion in Grain-Oriented Silicon Steel in Cyclic Magnetic Fields. Journal of Applied Physics. 1967;38(3):1089-1095.

18. Dijkstra LJ, Wert C. Effect of Inclusions on Coercive Force of Iron. Physical Review. 1950;79(6):979-985.

19. Gallaugher M, Ghosh P, Knight AM, Chromik RR. The effect of easy axis misorientation on the low induction hysteresis properties of non-oriented electrical steels. Journal of Magnetism and Magnetic Materials. 2015;382:124-133. 